\title{
Analysis and Development Forecast of Water Resources in China
}

\author{
Ning $E^{1, a}$, \\ ${ }^{1}$ Basic teaching and research department of Harbin finance university Xiang fang district Harbin China
}

\begin{abstract}
Based on the background of water shortage in Ningxia region, this paper studies the current situation and development prediction of water resources in China and establishes a regression analysis mode. Firstly, the current situation and major problems of water resources development and utilization in China were analyzed with Excel. Secondly, the regression model is established to predict the total national water consumption in 2020 and 2030, the results of the model prediction are compared with the national goals of 2020 and 2030. Finally, the ARIMA model was established by SPSS software to predict the time series and obtain the national and provincial water resource management and control and development trends in 2020 and 2030.
\end{abstract}

\section{The introduction}

In recent years, more people and less water and uneven spatial and temporal distribution of water resources are China's basic national conditions and water situation, the shortage of water resources, serious water pollution and deterioration of water ecology are very serious problems, which have become the main bottleneck of economic and social sustainable development. With the further development of industrialization and urbanization, the demand for water resources will continue to grow over a long period of time, the contradiction between supply and demand of water resources will be more acute, and the situation of water resources in China will be more serious.

\section{The present situation of development and utilization of water resources in China and its main problems}

According to the water resources bulletin 2012-2016, China's surface water resources and groundwater resources have little change each year, precipitation is greatly affected by other factors such as climate. See below.

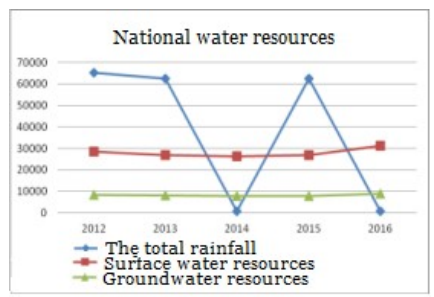

Figure 1. National water resources

The development and utilization of water resources situation in our country, from the national surface water exploitation and utilization of significantly more than the development and utilization of groundwater, mainly composed of surface water and groundwater is complementary, but different from the north-south geographical position, exploitation and utilization of six in the north area of surface water and groundwater development and utilization of a smaller gap was basically use at the same time, the status of exploitation and utilization of six in the south area of surface water and groundwater development and utilization of the gap is great, basic is in a state of only the surface water.

\subsection{Use SPSS to process the data}

Table 1. Anova

\begin{tabular}{|c|c|c|c|c|c|}
\hline Model & $\begin{array}{c}\text { Sum of } \\
\text { squares }\end{array}$ & df & $\begin{array}{c}\text { The mean } \\
\text { square }\end{array}$ & F & Sig \\
\hline $\begin{array}{c}\text { Return } \\
\text { to the }\end{array}$ & 6874.884 & 1 & 6874.884 & 5.026 & .111 \\
\hline Residual & 4103.596 & 3 & 1367.865 & & \\
\hline $\begin{array}{c}\text { A total } \\
\text { of }\end{array}$ & 10978.480 & 4 & & & \\
\hline
\end{tabular}

Conclusion $\mathrm{R}=0.791$ regression model

$$
\mathrm{Y}=-26.220+6189.260+\text { delta }
$$

(The total value of allowance is not large, which is negligible in the range of allowable error.)

\subsection{Compare the deviation with the target and make comparative analysis}

According to the water resources bulletin of 2012-2016, use the regression function to predict water consumption 
in 2020 and 2030, the national water consumption in 2020 is 606.639 .95 billion cubic meters, while that in 2030 is 602.521 .7 billion cubic meters, which is quite different from the national target of 2020 and 2030, The predicted value is smaller than the target value, which indicates that the water consumption will be effectively controlled under the existing control measures.

\section{Water consumption of ten thousand yuan of industrial added value}

For industrial water use efficiency in different parts of the situation, in a study period, the region may be at an early stage, may also be a stage of development, gradually to the late stage of development, it is possible that the experience of development, early and late three times, so this article take the various types of mathematical curve model to fitting was carried out on the water consumption per ten thousand yuan of value-added by industry series.

\subsection{Exponential model}

In assuming the added value of industrial water consumption of ten thousand yuan a year relative change rate of linear change, then you can get a general solution, but for a specific area, single years of water consumption per ten thousand yuan of value-added by industry relative rate of change due to random variation is very big, can't fully satisfy the assumption, in this case, can use moving average or the geometric average method to analyze the sequence of potential change rule. According to the relative change speed sequence of water consumption per 10,000 yuan of industrial added value per year in anhui province, it can't reflect its law well. After the geometric average every four years, the sequence has a linear change trend.

\subsection{Logistic model}

In describing the biological growth rule, a Logistic model is commonly used to describe and the meanings of the model as follows: when the early growth of a species, because of the space and the food is enough, then the relative growth rate is a constant value of species, but as the number of biological development to a certain extent, with the competition between species makes biological development space and food source is not enough, so the relative growth rate will slow, eventually biomass to a certain limit. If the development of industrial water efficiency in a certain region has experienced three stages, including initial stage, development stage and later stage, the Logistic model can be shifted symmetrically, and the water consumption sequence of 10,000 yuan of industrial added value in this region can be fitted with the formula obtained by the transformation. The specific transformation results are as follows

$$
P(t)=M^{\prime}+\frac{P_{0}^{\prime}}{1+\frac{M^{\prime}}{M^{\prime}-P_{0}^{\prime}} e^{k^{\prime} t}}
$$

We take the derivative of this

$$
\frac{d P}{d t}=-k(P-M)\left(1-\frac{P-M}{P_{0}}\right)
$$

It can be seen that the water consumption of ten thousand yuan of industrial added value decreased slowly in the initial stage, then the decline speed gradually increased, and finally slowed down, until reaching a certain stable lower limit.

\subsection{Other functions}

For the water consumption series of 10,000 yuan of industrial added value, the overall trend is downward, so other decline functions can also be used to try to fit the data series. From the actual data fitting, this paper recommends the following formula:

$$
W(t)=\frac{a}{t^{2}+b}
$$

The decline trend of the water consumption of ten thousand yuan of industrial added value can be predicted by the annual average decline rate, which is expressed as

$$
W_{t}=W_{0}(I-J)^{t}
$$

The added value of ten thousand yuan of industrial water consumption forecast based on the ten thousand 2010 water resources bulletin of the national and the provincial data of water consumption per ten thousand yuan of value-added by industry, and make use of national and provincial industrial production index, converts all water consumption per ten thousand yuan of value-added by industry in 2010, constant, using mathematical functions mentioned above, using the $\mathrm{m}$ atlab curve fitting toolbox curve $\mathrm{f}$ it - ting tool for curve fitting. Then, the water consumption of 10 thousand yuan of industrial added value in China and provinces was predicted by using the fitting function.

\subsection{Forecast of water consumption per 10,000 yuan of industrial added value}

Time series was used as the independent variable, water consumption of ten thousand industrial added value was used as the dependent variable, and 1997 was used as the first year for fitting, and the fitting result was expressed as

$$
y=288.3 e^{-0.08275 x}
$$

Formula (5) is used to predict the water consumption of 10,000 yuan of industrial added value nationwide. The calculation result is $598 \mathrm{rn} / 10,000$ yuan, which is lower than the target value of $63 \mathrm{~m} / 10,000$ yuan.

The same method was used to predict the wc per ten thousand yuan of industrial added value in all provinces in 2015. In the actual operation process, it was found that the wc per ten thousand yuan of industrial added value in Tibet autonomous region was not obvious. 


\section{Model evaluation and improvement}

\subsection{Model evaluation and improvement}

This model USES ARIMA model to predict the development trend of water resources management and control, according to the official website to find the data can be predicted in 2020-2030 of ten thousand yuan GDP water consumption, actual irrigation water consumption per acre of arable land and water consumption per ten thousand yuan of value-added by industry development trend, thus the rationality of the results and precision is very high, and we only, it is concluded that the calculation results for data request is not high.

\subsection{Disadvantages of the model}

We use the time series model in the prediction. The time series analysis prediction method is to predict the future development based on the past trend of the country and provinces, and its premise is that the past of things will continue to the future. Need to point out that, f series forecasting method for outstanding between time series of short duration does not consider outside factors, so there is a defect prediction error, when faced with the outside world, great changes have taken place tend to have larger deviation, the effect of the time series prediction method for short-term earthquake prediction than the long-term forecast effect is good, we get the model also exist significant is not strong, so need to be improved.

\section{Thank you}

This paper is one of the periodical achievements of the Heilongjiang provincial youth academic backbone project the dynamic model of measles infectious disease based on delay differential equation.

\section{References}

1. Xue Wei. SPSS based data analysis [M]. Beijing: Renmin university of China press, (2006: 107-121).

2. Han Zhonggeng. Mathematical modeling methods and their applications, Beijing: advanced education press, (2005).

3. Qin Xuhua. Technology innovation and application, discussion on improving utilization coefficient of irrigation water, issue $(08,2013)$.

4. Luo Bin. Research and application of a fast estimation method of software function scale based on linear regression analysis, university of national defense science and technology, (2013-05-01). 